\title{
Characterization of Legionella Species by Numerical Analysis of Whole-Cell Protein Electrophoresis
}

\author{
ANTÓNIO VERÍSSIMO, ${ }^{1}$ PAULA V. MORAIS, ${ }^{2}$ ALEXANDRA DIOGO, ${ }^{2}$ \\ CÉLIA GOMES, ${ }^{2}$ AND MILTON S. DA COSTA ${ }^{2 *}$ \\ Departamento de Zoologia, Universidade de Coimbra, 3049 Coimbra Codex, ${ }^{1}$ and Departamento de \\ Bioquímica, Universidade de Coimbra, 3000 Coimbra, ${ }^{2}$ Portugal
}

\begin{abstract}
The results of a computer-assisted whole-cell protein sodium dodecyl sulfate-polyacrylamide gel electrophoresis (SDS-PAGE) analysis of 291 isolates and 74 reference strains belonging to all known species of the genus Legionella revealed that the majority of the species of this genus can be adequately identified by this method. The type strain of Legionella bozemanii did not cluster with the other strains of this species, and the only strain of Legionella geestiana available clustered with the strains of Legionella feeleii. When we performed a numerical analysis by omitting certain portions of the pattern containing dense bands, all of the species could be distinguished. Our results also show that the type strains of Legionella nautarum and Legionella londiniensis deposited in the National Collection of Type Cultures do not correspond to the type strains deposited in the American Type Culture Collection. We used the results of a fatty acid and ubiquinone composition analysis to complement the SDS-PAGE results for several strains whose identities as determined by indirect immunofluorescence were doubtful. Computer-assisted SDS-PAGE of whole-cell proteins can be used in the classification of Legionella species and to identify and screen large numbers of isolates for further, in-depth taxonomic studies of smaller numbers of strains.
\end{abstract}

At this time, there are 39 validly described species and three subspecies in the family Legionellaceae $(2,5)$. Several of these organisms are responsible for Legionnaires' disease $(6,8,20)$ and Pontiac fever (10). Most authors place all of these species in the genus Legionella, although two other genera, the genus Tatlockia for Legionella micdadei and Legionella maceachemii and the genus Fluoribacter for Legionella bozemanii, Legionella dumoffii, and Legionella gormanii, have been validly described $(4,7,9)$. The large number of species and difficulties in distinguishing most of these species on the basis of phenotypic characteristics hinder the identification of strains belonging to the genus Legionella.

Serogrouping in which polyvalent antisera or monoclonal antibodies are used is the most common method used to identify Legionella species, and frequently, new species are recognized because isolates are not serologically reactive with the existing antisera. In many cases, species are divided into serogroups or monoclonal antibody subgroups mainly for clinical and epidemiological purposes $(12,34)$. However, the occurrence of cross-reactions can be misleading in the identification of Legionella species, and serological diversity is frequently observed in some species, particularly Legionella pneumophila, so the number of different antisera needed to identify isolates is cumbersome.

Cultural and biochemical characteristics $(31,32)$, including fatty acid compositions and quinone contents $(17,35)$, are useful in the identification of Legionella species, but in most cases these characteristics are useful only for assigning Legionella species to groups composed of several species. Multilocus enzyme electrophoresis, DNA fingerprinting, and ribotyping can be used to distinguish most of the Legionella species that have been examined, but these techniques have not been used extensively and are too time consuming for rapid identification of these organisms $(1,11,22,23,36)$. In many cases, whole-

\footnotetext{
* Corresponding author. Mailing address: Departamento de Bioquímica, Apartado 3126, Universidade de Coimbra, 3000 Coimbra Portugal. Phone: 351-39-24024. Fax: 351-39-26798.
}

genome DNA-DNA hybridization is the only method used to describe and conclusively identify Legionella species $(3,5)$, but this technique is difficult to use with a large number of isolates.

Protein sodium dodecyl sulfate (SDS)-polyacrylamide gel electrophoresis (PAGE) has also been used with several Legionella species, but the comparisons were limited to visual observations of the gels and the method could not be used with large numbers of isolates $(18,25)$. It has been established that computer-aided comparisons of whole-cell electrophoretic protein patterns provide a reliable way to measure genomic relatedness that is comparable to DNA-DNA hybridization in other bacteria $(13,27)$. The main advantage of numerical analysis of whole-cell electrophoretic protein patterns is that large numbers of bacterial strains can be compared by a relatively rapid, reliable, high-resolution method. Another advantage of this method is the fact that it is possible to store digitally processed electrophoretic traces of representative strains on computer files and to use these traces to construct large databases which can be used to identify new isolates.

In this study we performed a computer-assisted comparison of whole-cell protein profiles generated by SDS-PAGE and developed a simple and reliable procedure to identify isolates of Legionella spp. and to determine the potential use of this method in the systematics of these organisms. Below we describe the results of a numerical analysis in which we used the protein profiles of 365 isolates and reference strains that were representative of all of the Legionella species that have been described.

\section{MATERIALS AND METHODS}

Bacterial strains. The strains which we examined and their origins are shown in Table 1. A total of 261 isolates were recovered by us from thermal springs, thermal spring runoffs, thermal spas, plumbing systems, neonatal incubators, and lung aspirates. Thirty strains whose designations begin with $\mathrm{Ch}$ were kindly donated and identified (by immunofluorescence [IFA]) by the National Legionella Reference Laboratory, Vyskov, Czech Republic. The vast majority of the isolates were identified by the indirect IFA method by using the antisera described previously $(19,29,30)$. However, 31 of our isolates, most of which were obtained from the hot spring designated LA, and 11 isolates whose designations begin with $\mathrm{Ch}$ could not be identified by the IFA technique. All strains were 
TABLE 1. Legionella strains examined in this study, organized on the basis of SDS-PAGE groups

\begin{tabular}{|c|c|}
\hline Cluster & $\begin{array}{l}\text { Taxon as determined } \\
\text { by SDS-PAGE }\end{array}$ \\
\hline $\begin{array}{l}1 \\
2 \\
3 \\
4\end{array}$ & $\begin{array}{l}\text { L. anisa } \\
\text { Legionella } \mathrm{sp} . \\
\text { L. dumoffii } \\
\text { L. bozemanii }\end{array}$ \\
\hline 5 & L. sainthelensi \\
\hline 6 & L. longbeachae \\
\hline 7 & L. jordanis \\
\hline 8 & L. birminghamensis \\
\hline 9 & L. erythra \\
\hline 10 & L. nubrilucens \\
\hline 11 & L. oakridgensis \\
\hline 12 & L. gormanii \\
\hline 13 & L. steigerwaltii \\
\hline 14 & L. cherrii \\
\hline 15 & L. pneumophila \\
\hline
\end{tabular}

L. feeleii-L. geestiana

L. hackeliae

L. brunensis

L. moravica

L. micdadei

L. nautarum

L. londiniensis
Reference strains and isolates as identified by IFA ${ }^{a}$

L. anisa ATCC $35292^{\mathrm{T}}$ and $\mathrm{Cu}-10$; unidentified strain $\mathrm{Ch}-35$

Unidentified strains Ch-32, Ch-33, Ch-36, Ch-37, and Ch-39

L. dumoffii ATCC $33279^{\mathrm{T}}$, Iz-16, Iz-110, Iz-122, Iz-186, Iz-193, and SG-155

L. bozemanii serogroup 2 strains ATCC 35545, CAMR 1723, Cu-7, Iz-36, Iz-313, Iz-315, and Iz-317; unidentified strains Ch-34, Ch-38, and Ch-40

34 L. sainthelensi ATCC $35248^{\mathrm{T}}$, Aço-66, and Iz-21; L. santicrucis Ed-4a and Iz-86; unidentified strains La-2, La-3, La-4, La-5, La-6, La-7, La-8, La-9, La-10, La-11, La-12, La-13, La-14, La-15, La-16, La-17, La-18, La-20, La-21, La-22, La-24, La-25, La-27, La-28, La-29, La-30, La-31, La-32, and La-33

$5 \quad$ L. longbeachae serogroup 1 strains ATCC $33462^{\mathrm{T}}$, NCTC $11477^{\mathrm{T}}$, and Ch- $29 ;$ L. longbeachae serogroup 2 strains ATCC 33484 and NCTC 11530

L. jordanis ATCC $33623^{\mathrm{T}}$, Ch-13, and Ch-14

L. birminghamensis ATCC $43702^{\mathrm{T}}$, Ch- 25 , and Ch- 26

L. erythra ATCC $35303^{\mathrm{T}}$, Ch-3, and Ch-4; L. rubrilucens Ch-1 and Ch-2; L. spiritensis Ch-15

L. rubrilucens ATCC $35304^{\mathrm{T}}$; L. spiritensis Ch-16 and Ch-17

L. oakridgensis ATCC $33761^{\mathrm{T}}$, Ch-18, Cu-5, Iz-62, Iz-65, Iz-66, Iz-221, Iz-318, Iz-319, and Iz-320

L. gormanii ATCC $33297^{\mathrm{T}}$ and $\mathrm{Ch}-21$

L. steigenwaltii ATCC $35302^{\mathrm{T}}$; L. gormanii Ch-22

L. cherrii ATCC $35252^{\mathrm{T}}$; unidentified strains Ch-23 and Ch-24

L. pneumophila serogroup 1 strains ATCC $33152^{\mathrm{T}}$, ATCC 33153, ATCC 43106, ATCC 43107, ATCC 43108, ATCC 43109, ATCC 43110, ATCC 43111, ATCC 43112, ATCC 43113, Agn-2, Agn-4, Agn-6, Agn-8, Agn-9, Agn-11, Alf-1, Alf-18, Alf-31, Alf-33, Alf-44, Alf-47, Alf-55, Alf-60, Alf-73, Alf-82, Alf-85, Ed-7, Ed-12, Ed-17, Ed-21, Hrd-1, Hrd-4, Ice-1, Ice-2, Ice-8, Ice-11, Ice-12, Ice-23, Ice-24, Ice-50, IMC-1, IMC-2, IMC-3, IMC-4, IMC-5, IMC-6, IMC-7, IMC-8, IMC-9, IMC-10, IMC-11, IMC-12, IMC-14, IMC-16, IMC17, IMC-18, IMC-19, IMC-21, IMC-22, IMC-23, IMC-24, Iz-7, Iz-22, Iz-23, Iz-28, Iz-32, Iz-41, Iz-47, Iz-58, Iz-68, Iz-69, Iz-70, Iz-90, Iz-95, Iz-115, Iz-151, Iz-155, Iz-164, Iz-220, Iz-232, Iz-235, Iz-249, Iz-258, Iz-269, Iz-287, Iz-290, NMex-35, NMex-64, NMex-104, NMex-125, NMex-141, NMex-157, NMex-166, NMex-173, SG-3, SG-19, SG-29, SG-45, SG-47, SG-67, SG-83, SG-123, and SG-138; serogroup 2 strains ATCC 33154, Aço-15, Aço-42, Alf-2, Iz-2, Iz-35, NMex-22, and NMex-75; serogroup 3 strains ATCC 33155, Aço-13, Aço-22, Ed-8, Ed-13, Ed-28, Iz-5, Iz-8, Iz-18, Iz-78, Iz-148, NMex-18, NMex-66, SG-4, SG-25, SG-66, SG-131, and SG-251; serogroup 4 strain ATCC $33156^{\mathrm{T}}$; serogroup 5 strains ATCC 33216, ATCC 33735, ATCC 33736, ATCC 33737 ${ }^{\mathrm{T}}$, and SG-13; serogroup 6 strains ATCC 33215, Aço-20, Aço-52, Aço-65, Aço-68, Alf-12, Ice-65, Iz-67, Iz-108, Iz130, Iz-282, Iz-293, NMex-1, NMex-6, NMex-27, NMex-28, SG-69, and SG-150; serogroup 7 strain ATCC 33823; serogroup 8 strains ATCC 35096, Aço-8, Alf-32, Ed-32, Ice-10, Ice25, Ice-34, Ice-45, Ice-60, Ice-69, Iz-49, Iz-152, Iz-177, and SG-24; serogroup 9 strain ATCC 35289; serogroup 10 strains ATCC 43283, Alf-45, Ed-36b, Ice-13, Ice-30, Ice-48, Ice-74, Iz-42, Iz-51, Iz-56, Iz-89, Iz-158, Iz-173, and SG-18; serogroup 11 strain ATCC 43130; serogroup 12 strains ATCC 43290, Iz-268, NMex-108, NMex-136, and NMex-158; serogroup 13 strains ATCC 43736, Aço-9, Aço-33, and NMex-149; serogroup 14 strains ATCC 43703, Agn-3, Agn-5, Agn-7, and Agn-10; serogroup 15 strain ATCC 35251

L. feeleii serogroup 1 strains ATCC $35072^{\mathrm{T}}$ and CAMR 1717; L. feeleii serogroup 2 strain ATCC 35849; L. geestiana ATCC $49504^{\mathrm{T}}$

L. hackeliae serogroup 1 strain ATCC $35250^{\mathrm{T}} ;$ L. hackeliae serogroup 2 strain ATCC 35999

L. brunensis ATCC $43878^{\mathrm{T}}$, Ch-9, Ch-10, and Ch-12

L. moravica ATCC $43877^{\mathrm{T}}$ and Ch-19

L. micdadei ATCC 33218 ${ }^{\mathrm{T}}$, ATCC 33204, Aço-69, SG-157, SG-168, SG-175, SG-188, SG224, and SG-238

L. nautarum ATCC $49506^{\mathrm{T}}$; L. londiniensis NCTC $12374^{\mathrm{T}}$ and Ch-5

L. londiniensis ATCC 49505 ${ }^{\mathrm{T}}$, Alf-40, Alf-50, Iz-9, Iz-10, Iz-11, Iz-24, Iz-25, Iz-30, Iz-31, Iz97, Iz-98, Iz-99, Iz-102, Iz-103, Iz-104, Iz-124, Iz-195, Iz-206, Iz-210, Iz-306, Iz-308, and Iz-310; L. nautarum NCTC $12375^{\mathrm{T}}$ and Ch-20; unidentified strains Iz-84 and Iz-200

L. adelaidensis ATCC $49625^{\mathrm{T}}, L$. bozemanii serogroup 1 strain ATCC $33217^{\mathrm{T}}, L$. cincinnatiensis ATCC $43753^{\mathrm{T}}$, L. fairfieldensis ATCC $49588^{\mathrm{T}}$, L. gratiana ATCC $49413^{\mathrm{T}}, L$. israelensis ATCC $43119^{\mathrm{T}}$, L. jamestowniensis ATCC $35298^{\mathrm{T}}$, L. lansingensis ATCC $49751^{\mathrm{T}}$, L. maceachernii ATCC $35300^{\mathrm{T}}$, L. parisiensis ATCC $35299^{\mathrm{T}}$, L. quateirensis ATCC $49507^{\mathrm{T}}$, L. quinlivanii ATCC $43830^{\mathrm{T}}$, L. santicrucis ATCC $35301^{\mathrm{T}}$, L. shakespearei ATCC $49655^{\mathrm{T}}$, L. spiritensis ATCC $35249^{\mathrm{T}}$, L. tucsonensis ATCC $49180^{\mathrm{T}}$, L. wadsworthii ATCC $33877^{\mathrm{T}}$, L. worsleiensis ATCC $49508^{\mathrm{T}}$

\footnotetext{
"Origins of the strains: ATCC, American Type Culture Collection, Rockville, Md.; CAMR, Centre for Applied Microbiology and Research, Salisbury, United Kingdom; NCTC, National Collection of Type Cultures, London, United Kingdom; Aço, hydrothermal area, Azores, Portugal; Agn, hydrothermal area, southern Italy; Alf, hydrothermal area, central Portugal; Ch, manmade environments, Prague, Czech Republic; $\mathrm{Cu}$, hydrothermal area, central Portugal; Ed, hydrothermal area, central Portugal; HRD, lung aspirate, Coimbra, Portugal; Ice, hydrothermal areas, Iceland; IMC, neonatology unit, pediatric hospital, Coimbra, Portugal; Iz, hydrothermal area, northern Portugal; La, hydrothermal area, northern Portugal; NMex, hydrothermal area, New Mexico; SG, hydrothermal area, central Portugal.
} 


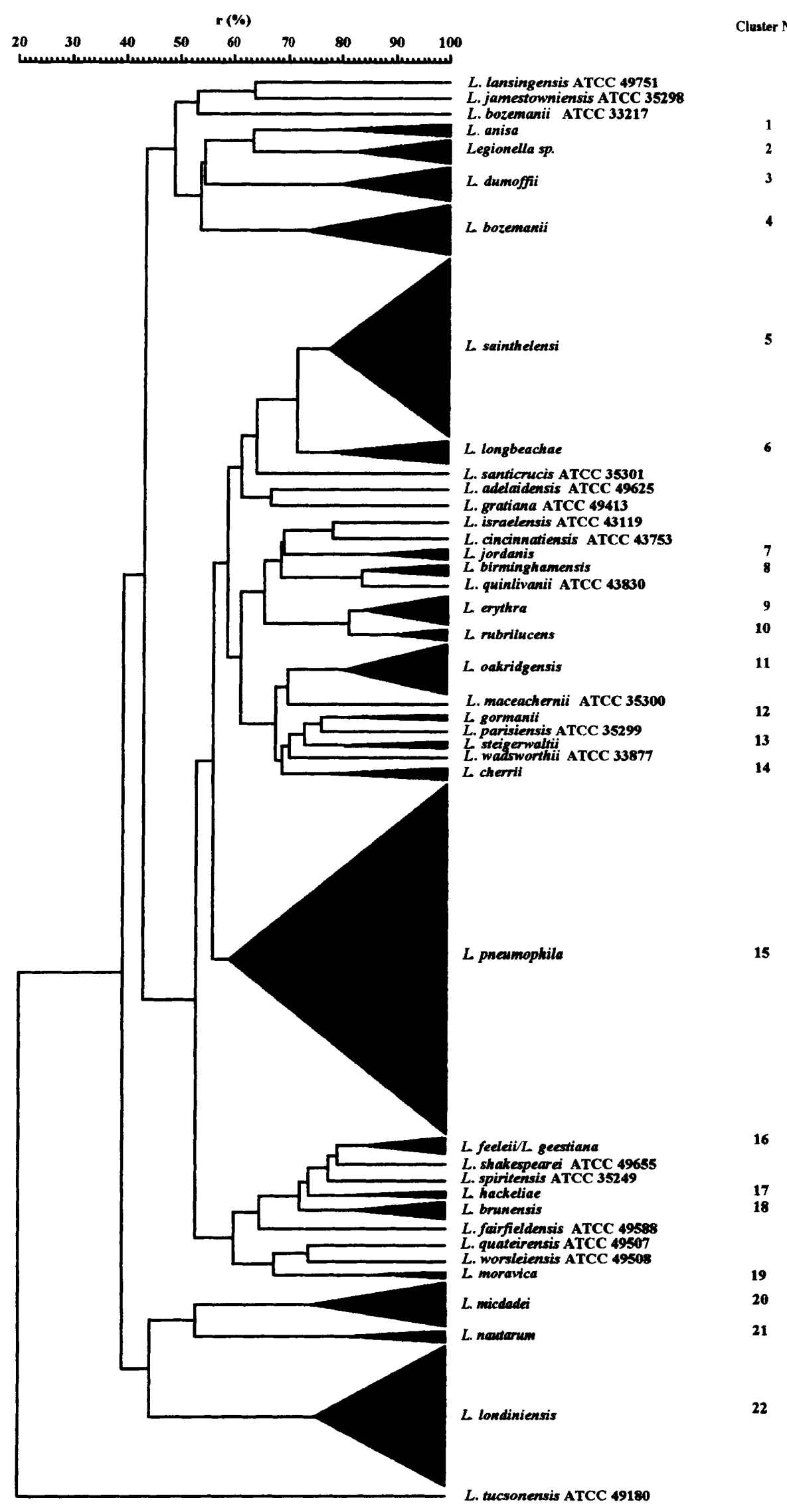

FIG. 1. Dendrogram based on unweighted pair group average linkage of correlation coefficients ( $\mathrm{r}$ ) of the protein patterns. The dendrogram was produced by using points 10 to 330 on the electrophoretic traces obtained for the strains listed in Table 1. All of the unclustered strains are type strains. 
cultured on buffered charcoal-yeast extract- $\alpha$-ketoglutarate medium at $37^{\circ} \mathrm{C}$ for $72 \mathrm{~h}$ in sealed plastic bags (29) and were maintained at $-80^{\circ} \mathrm{C}$ in $5.0 \%$ (wt/vol) yeast extract containing $15.0 \%(\mathrm{vol} / \mathrm{vol})$ glycerol.

Preparation of protein samples and PAGE. Whole-cell protein extracts were prepared as described previously (14). Supernatants were stored at $-20^{\circ} \mathrm{C}$ for short-term use and were kept at $-80^{\circ} \mathrm{C}$ for long-term storage. SDS-PAGE of the whole-cell protein extracts was performed by the procedure of Laemmli (16), as modified by Kiredjian et al. (14), at $10^{\circ} \mathrm{C}$ and a constant current of $16 \mathrm{~mA}$ in a model SE600 electrophoresis apparatus (Hoefer).

Numerical analysis of the protein electropherograms. Protein electrophoretic patterns were scanned with a model XL Ultroscan laser densitometer (LKB Bromma, Sweden). An objective comparison and normalization of the lanes on different slab gels were achieved by including a protein extract of Psychrobacter immobilis LMG 1125 (Laboratorium voor Microbiologie, Universiteit Gent, Ghent, Belgium) as a reference four times in each gel. A densitometric analysis, normalization and interpolation of the protein profiles, a numerical analysis, and construction of the database were performed by using the PC-Windows software package GelCompar (version W3.0; Applied Maths, Kortrijk, Belgium) as described previously (28). The levels of similarity between pairs of traces were computed by using the Pearson product-moment correlation coefficient, and data were clustered by using the unweighted pair group method with arithmetic average algorithm (24). Unless indicated otherwise, the numerical analysis was performed by using points 10 to 330 of the 400 points obtained for each interpolated trace.

Ubiquinone and fatty acid analyses. Ubiquinones were extracted from freezedried cells and were purified by thin-layer chromatography as described by Tindall (26). The lipoquinones were separated with a Gilson high-performance liquid chromatography apparatus by using a reverse-phase (RP18) column (Spherisorb S5 ODS2) and methanol-heptane (10:2, vol/vol) as the mobile phase and were detected at $270 \mathrm{~nm}$.

The cultures used for the fatty acid analysis were grown as described above. Fatty acid methyl esters were obtained from fresh wet biomass by saponification methylation, and extraction (15). The fatty acid methyl esters were separated with a Hewlett-Packard model 5890 gas chromatograph by using the Microbial Identification System MIDI protocol (Microbial ID, Inc., Newark, Del.). Fatty acid methyl esters were identified and quantified and a numerical analysis of the fatty acid profiles was performed by using the MIDI software package.

\section{RESULTS AND DISCUSSION}

The reproducibility of the protein electrophoretic technique was verified by using $P$. immobilis LMG 1125 , and only the gels with levels of similarity of $93 \%$ or more (mean, $95 \%$ ) were used for the numerical analysis. Our numerical analysis of the whole-cell SDS-PAGE profiles of 365 strains resulted in the formation of 22 clusters, and 18 strains did not belong to any cluster (Fig. 1). In most cases the clusters corresponded to Legionella species, while 17 of the unclustered strains belonged to species represented by type strains alone. However, the type strain of $L$. bozemanii (ATCC 33217) and the reference strain for serogroup 1 reference strain were not included in cluster 4 with $L$. bozemanii serogroup 2 strain ATCC 35545 or with any of the other isolates identified as $L$. bozemanii regardless of their identification as serogroup 1 or 2 strains by IFA. The division of the strains of this species in the numerical analysis was due to the presence of one intense band in $L$. bozemanii ATCC $33217^{\mathrm{T}}$ ( $\mathrm{T}=$ type strain) between points 160 and 190 on the electrophoretic trace (Fig. 2). After the corresponding zone was removed from the numerical analysis, all of the $L$. bozemanii strains examined in this study formed one cluster at a similarity level of $80 \%$. The removal of this zone from the numerical analysis did not influence the formation of any of the other clusters, but we chose not to exclude this zone, because only one $L$. bozemanii strain that produced this protein profile was available, and this was not sufficient to confirm the cause for the division of this species into two electrophoretic groups. On the other hand, Legionella geestiana ATCC $49504^{\mathrm{T}}$ could not be distinguished from the three $L e$ gionella feeleii strains (cluster 16) by the results of the standard numerical analysis which we used. The strains of these two species could be separated from each other without affecting any of the other clusters when points 76 to 103 were omitted from the numerical analysis. This zone included a dense band

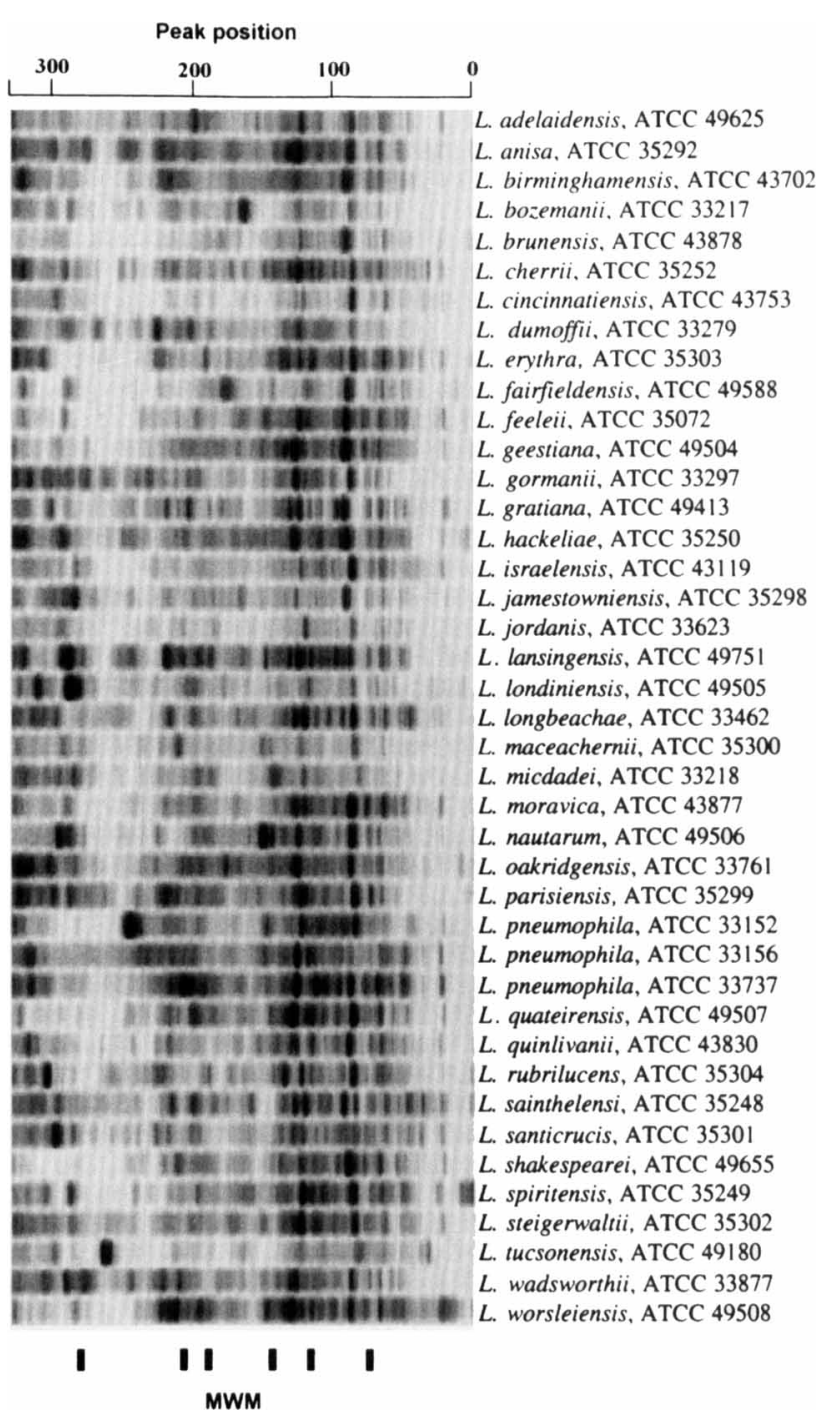

FIG. 2. Computer-generated normalized electrophoretic protein patterns of all of the type strains of members of the genus Legionella. The positions of the molecular weight markers (MWM) are indicated at the bottom. The molecular weight markers used were (from left to right) trypsin inhibitor (molecular weight, $20,100)$, trypsinogen $(24,000)$, carbonic anhydrase $(29,000)$, glyceraldehyde-3phosphate dehydrogenase $(36,000)$, egg albumin $(45,000)$, and bovine albumin $(66,000)$.

that was present in all strains. The major ubiquinones of these two species were also similar (Table 2), but the fatty acid compositions could be used to distinguish $L$. feeleii from $L$. geestiana (Table 3) and were consistent with the results of Dennis et al. (5).

A total of 27 reference strains and 173 isolates identified on the basis of serology as Legionella pneumophila strains formed one cluster (cluster 15) at a similarity level of $60 \%$. The low level of similarity of the strains of this species was due to a zone corresponding to points 226 to 259 that contained one major band in several strains. Elimination of this zone resulted in a cluster with a similarity level of $71 \%$ for all of the strains examined. Nevertheless, L. pneumophila has been considered heterogeneous, and it has been argued that three species could be described for L. pneumophila strains on the basis of wholegenome DNA-DNA hybridization data (2). The same conclusion was reached by using multilocus electrophoretic analysis data (23). On the basis of these considerations the species $L$. 
TABLE 2. Ubiquinone compositions of selected Legionella type strains and isolates

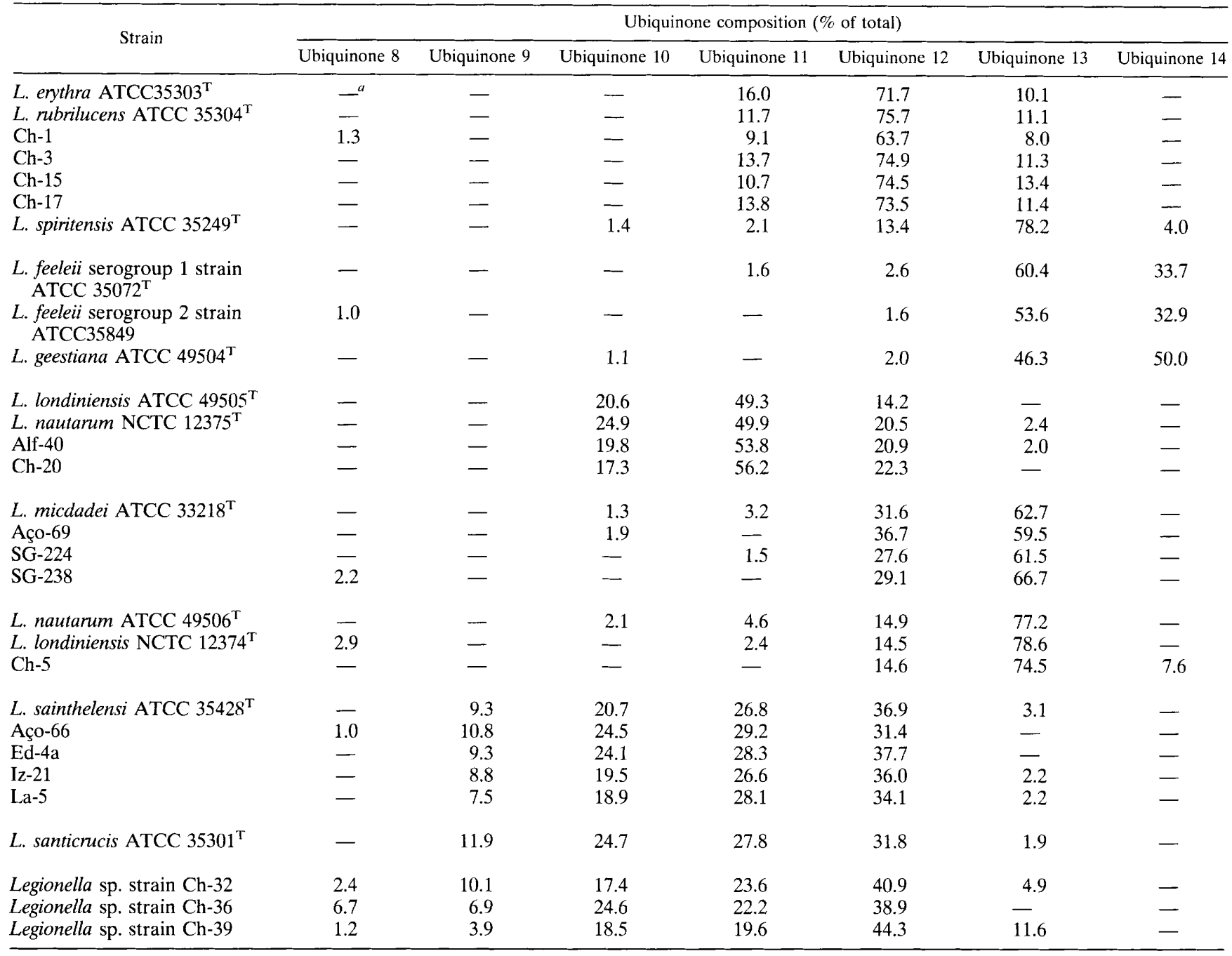

$a_{-}$, not detected or less than $1 \%$ of the total.

pneumophila was subdivided into three subspecies, L. pneumophila subsp. pneumophila, $L$. pneumophila subsp. fraseri, and $L$. pneumophila subsp. pascullei (2).

A numerical analysis performed with the 27 reference strains of L. pneumophila in which we used points 10 to 226 and 259 to 330 of the electrophoretic traces revealed that the strains of each of the three subspecies formed a subcluster. One subcluster, which was defined at a similarity level of $80 \%$, included strains previously assigned to L. pneumophila subsp. pneumophila. The two other subclusters, which were defined at levels of similarity of 88 and $90 \%$, included the strains of $L$. pneumophila subsp. fraseri and L. pneumophila subsp. pascullei, respectively (Fig. 3 ). The low level of similarity obtained for the subcluster containing the reference strains of $L$. pneumophila subsp. pneumophila may reflect a higher level of diversity within this subspecies.

When the same type of numerical analysis was applied to the reference strains and field isolates, the same general subclusters were obtained (data not shown), although none of the field isolates formed a subcluster with the strains of $L$. pneumophila subsp. fraseri or L. pneumophila subsp. pascullei. Nine isolates identified by IFA as members of L. pneumophila serogroups 1 ,
2,3 , and 8 , which were isolated from hot springs in Iceland, the Azores, and continental Portugal, and L. pneumophila serogroup 11 strain ATCC 43130 could not be included in the subclusters corresponding to the three subspecies of $L$. pneumophila. However, because of the high levels of similarity of these isolates with $L$. pneumophila and the IFA results, we considered them members of this species.

Our results also revealed that the serogroups of L. pneumophila do not correspond to particular electrophoretic profiles, which confirmed previous results $(2,23)$. L. pneumophila strains with similarity coefficients of more than 93 to $95 \%$, which generally originated from the same site or sites within restricted geographical areas $(19,29)$ and belonged to the same serogroup, formed subclusters at extremely high levels of similarity and presumably had clonal origins.

Six isolates identified as $L$. dumoffii strains were recovered in cluster 3 along with $L$. dumoffii ATCC $33279^{\mathrm{T}}$. Two blue-white autofluorescent strains (strains $\mathrm{Ch}-23$ and Ch-24) formed a cluster (cluster 14) with Legionella cherrii ATCC $35252^{\mathrm{T}}$ at a level of similarity of $79 \%$. These isolates were received by us as $L$. dumoffii strains, but they could not be identified by us by IFA. Moreover, these isolates could not be tentatively assigned 
TABLE 3. Fatty acid compositions of selected Legionella type strains and isolates

\begin{tabular}{|c|c|c|c|c|c|c|c|c|c|c|c|}
\hline \multirow{2}{*}{ Strain } & \multicolumn{11}{|c|}{ Fatty acid composition (\%) } \\
\hline & il4:0 & Summed feature $1^{a}$ & $\mathrm{n} 14: 0$ & i15:0 & a15:0 & $15: 1 \omega 6 c$ & n15:0 & $\mathrm{i} 16: 1 \mathrm{H}^{b}$ & $16: 1 \omega 7 \mathrm{c}$ alcohol & $\mathrm{i} 16: 0$ & $16: 1 \omega 11 \mathrm{c}$ \\
\hline L. erythra ATCC $35303^{\mathrm{T}}$ & 2.88 & $-{ }^{c}$ & - & - & 11.46 & 2.96 & 1.44 & - & - & 31.83 & - \\
\hline L. rubrilucens ATCC $35304^{\mathrm{T}}$ & 4.49 & - & - & - & 15.64 & 3.56 & 1.79 & 1.04 & - & 38.34 & - \\
\hline Ch-1 & 3.44 & - & - & - & 13.93 & 2.12 & 1.22 & - & - & 31.86 & - \\
\hline Ch-3 & 3.58 & - & - & - & 12.43 & 2.77 & 2.81 & - & - & 30.51 & - \\
\hline Ch-15 & 3.63 & - & - & - & 18.41 & 2.07 & - & 2.83 & - & 30.00 & 一 \\
\hline Ch-17 & 3.18 & - & - & - & 16.83 & 1.96 & - & 3.03 & - & 29.38 & - \\
\hline L. spiritensis ATCC $35249^{\mathrm{T}}$ & 3.09 & - & - & - & 19.26 & - & - & 5.13 & - & 31.89 & - \\
\hline $\begin{array}{l}\text { L. feeleii serogroup } 1 \text { strain } \\
\text { ATCC } 35072^{\mathrm{T}}\end{array}$ & 6.19 & - & - & - & 24.12 & 3.88 & 2.60 & - & 3.41 & 20.51 & 1.93 \\
\hline $\begin{array}{l}\text { L. feeleii serogroup } 2 \text { strain } \\
\text { ATCC } 35849\end{array}$ & 4.29 & - & - & - & 21.98 & 1.75 & - & - & 2.84 & 25.18 & 1.24 \\
\hline L. geestiana ATCC $49504^{\mathrm{T}}$ & - & 1.84 & 2.60 & 20.33 & 9.35 & 1.49 & 1.31 & - & - & - & - \\
\hline L. londiniensis ATCC $49505^{\mathrm{T}}$ & - & - & - & 2.18 & 9.98 & 2.82 & 1.18 & - & - & 17.17 & - \\
\hline L. nautarum NCTC $12375^{\mathrm{T}}$ & - & - & - & 1.76 & 9.45 & 3.03 & 1.17 & - & - & 19.34 & - \\
\hline Alf- 40 & - & - & - & - & 10.03 & 3.26 & 2.14 & - & - & 18.45 & - \\
\hline Ch-20 & - & - & - & - & 11.01 & 2.95 & 1.04 & - & - & 18.66 & - \\
\hline L. micdadei ATCC $33218^{\mathrm{T}}$ & - & - & - & 1.10 & 37.93 & 2.09 & 2.16 & 2.08 & - & 12.19 & - \\
\hline Aço-69 & 1.04 & - & - & - & 37.36 & 2.74 & 2.51 & 3.12 & - & 13.46 & - \\
\hline SG-224 & 1.16 & - & - & 1.03 & 40.23 & 2.75 & 2.50 & 2.67 & - & 12.66 & - \\
\hline SG-238 & 1.06 & - & - & 1.15 & 40.93 & 1.08 & 1.27 & 2.11 & - & 13.59 & - \\
\hline L. nautarum ATCC $49506^{\mathrm{T}}$ & 5.14 & 1.15 & 1.27 & - & 39.36 & 6.22 & 1.83 & - & - & 17.77 & - \\
\hline L. londiniensis NCTC $12374^{\mathrm{T}}$ & 2.60 & 1.29 & 1.66 & - & 33.65 & 4.41 & 2.52 & - & - & 12.42 & - \\
\hline Ch-5 & 2.78 & 1.26 & 2.31 & - & 36.81 & 3.92 & 2.56 & - & - & 12.26 & - \\
\hline L. sainthelensi ATCC $35248^{\mathrm{T}}$ & 9.45 & - & - & - & 20.69 & 3.91 & 1.34 & - & - & 18.15 & - \\
\hline Aço-66 & 8.13 & - & 1.05 & - & 11.58 & 2.35 & 2.16 & - & - & 23.64 & - \\
\hline Ed-4a & 6.16 & - & 1.36 & - & 13.97 & 3.82 & 3.10 & - & - & 16.62 & - \\
\hline Iz-21 & 6.38 & - & 1.03 & - & 15.43 & 3.95 & 2.67 & - & - & 17.60 & - \\
\hline $\mathrm{La}-5$ & 7.45 & - & 1.03 & - & 11.82 & 2.30 & 1.74 & - & - & 22.22 & - \\
\hline L. santicrucis ATCC $35301^{\mathrm{T}}$ & 15.27 & - & - & - & 13.56 & 2.90 & 1.82 & - & - & 26.72 & - \\
\hline Legionella sp. strain Ch- 32 & 2.59 & - & - & - & 30.05 & - & 1.22 & - & - & 17.10 & - \\
\hline Legionella sp. strain Ch-36 & 2.82 & - & - & - & 28.94 & 1.18 & 1.61 & - & - & 18.00 & - \\
\hline Legionella sp. strain Ch-39 & 2.35 & - & - & - & 38.37 & 1.71 & 2.23 & - & - & 11.53 & - \\
\hline
\end{tabular}

${ }^{a}$ Group of fatty acids $(14: 1 \omega 5 \mathrm{c}, 14: 1 \omega 5 \mathrm{t})$ that cannot be reliably separated by the method which we used.

${ }^{b}$ The double bond position, indicated by the capital letter, is unknown.

$c-$, not detected or less than $1 \%$ of the total.

to any species on the basis of fatty acid composition and ubiquinone analysis data, because these chemotaxonomic parameters do not distinguish the blue-white autofluorescent species (35). Cluster 2 comprised five blue-white autofluorescent strains that were isolated from tap water in hotels, hospitals, and dormitories in the Czech Republic and could not be identified by IFA. This cluster formed at a similarity level of $83 \%$, but did not contain any of the reference strains examined in this study. The isolates belonging to this cluster formed a homogeneous group on the basis of fatty acid composition and respiratory quinone analysis data (Tables 2 and 3 ). The cluster 2 strains may represent a different electrophoretic type of a known species or an undescribed Legionella species.

L. gormanii ATCC $33297^{\mathrm{T}}$ and another isolate from the Czech Republic identified by IFA as a strain of this species formed cluster 12 . Cluster 13 , which formed at a similarity level of $81 \%$, included the type strain of Legionella steigerwaltii (ATCC 35302) and another strain identified by IFA as a $L$. gormanii strain. The isolates identified as Legionella birminghamensis and Legionella oakridgensis strains formed clusters with the type strains of these species at levels of similarity of $85 \%$ (cluster 8 ) and $81 \%$ (cluster 11 ), respectively.
Clusters 9 and 10 contained the type strains of the red autofluorescent species Legionella erythra (ATCC 35303) and Legionella rubrilucens (ATCC 35304), respectively. Two isolates identified by IFA as $L$. erythra, two isolates identified as $L$. rubrilucens, and one isolate identified as Legionella spiritensis were also recovered in cluster 9 at a similarity level of $84 \%$. At a level of similarity of $90 \%$, isolates $\mathrm{Ch}-16$ and $\mathrm{Ch}-17$, both of which were identified by IFA as $L$. spiritensis strains, formed a cluster with $L$. rubrilucens ATCC $35304^{\mathrm{T}}$. One isolate received as an L. spiritensis strain (Ch-16) exhibited red autofluorescence, but two other strains did not. Ubiquinone 12 was the major respiratory quinone in these three strains, whereas ubiquinone 13 is the major quinone in $L$. spiritensis ATCC $35249^{\mathrm{T}}$ (Table 2), which confirmed the SDS-PAGE protein identification of these three isolates as L. erythra or $L$. rubrilucens strains. The absence of red autofluorescence in $L$. erythra and $L$. rubrilucens strains is rare but has been described previously (35). Although we decided to place $L$. erythra and $L$. rubrilucens strains in separate clusters, these two species are clearly closely related as determined by a numerical analysis of whole-protein SDS-PAGE. Moreover, DNA-DNA hybridization also revealed that although the type strains of $L$. erythra 
TABLE 3-Continued

\begin{tabular}{|c|c|c|c|c|c|c|c|c|c|c|c|c|c|}
\hline \multicolumn{14}{|c|}{ Fatty acid composition (\%) } \\
\hline $16: 1 \omega 7 \mathrm{c}$ & $16: 1 \omega 5 \mathrm{c}$ & n16:0 & $\mathrm{i} 15: 03 \mathrm{OH}$ & $\mathrm{i} 17: 1 \omega 9 \mathrm{c}$ & a17:1 $\omega 9 \mathrm{c}$ & i17:0 & a17:0 & $17: 0$ cyclo & $\mathrm{n} 17: 0$ & $16: 12 \mathrm{OH}$ & $\mathrm{i} 16: 03 \mathrm{OH}$ & $\mathrm{n} 18: 0$ & $\mathrm{n} 19: 0$ \\
\hline 23.09 & - & 5.00 & - & - & - & 1.83 & 11.55 & - & 1.93 & - & - & 1.16 & - \\
\hline 15.63 & - & 3.22 & - & - & - & - & 10.11 & - & 1.44 & - & - & - & - \\
\hline 21.81 & - & 8.75 & - & - & - & - & 9.12 & - & 1.34 & - & - & 1.45 & - \\
\hline 23.58 & - & 6.29 & - & - & - & 1.49 & 9.58 & - & 1.48 & - & - & 1.07 & - \\
\hline 21.59 & - & 6.89 & - & - & 1.01 & - & 8.01 & - & 一 & - & - & - & - \\
\hline 20.42 & - & 8.97 & - & - & 1.20 & - & 8.35 & - & 1.12 & - & - & - & - \\
\hline 14.68 & - & 4.09 & - & - & 2.83 & - & 13.14 & - & - & - & - & - & - \\
\hline 19.91 & - & 7.41 & - & - & - & - & 4.54 & - & - & - & - & - & - \\
\hline 16.54 & - & 7.30 & - & - & - & - & 10.02 & - & - & - & - & - & - \\
\hline 33.13 & 一 & 15.13 & 1.20 & - & - & 4.95 & 2.71 & - & - & - & - & - & - \\
\hline 20.64 & - & 4.73 & - & 3.99 & - & 3.47 & 22.18 & - & 3.10 & - & - & 2.89 & 1.26 \\
\hline 19.22 & - & 4.09 & - & 4.02 & - & 3.18 & 23.40 & - & 3.29 & - & - & 2.46 & 1.42 \\
\hline 20.29 & - & 7.92 & - & - & - & - & 21.48 & - & 4.25 & - & - & 3.56 & 2.09 \\
\hline 19.18 & - & 4.01 & - & 1.81 & - & 1.48 & 27.88 & - & 4.22 & - & - & 2.22 & 1.11 \\
\hline 6.16 & - & 4.34 & - & - & 5.18 & - & 17.06 & 3.43 & - & 1.97 & - & - & - \\
\hline 10.71 & - & 4.76 & - & - & 5.29 & - & 13.70 & 1.94 & - & - & - & - & - \\
\hline 9.07 & - & 4.53 & - & - & 4.81 & - & 14.12 & 2.53 & - & 1.17 & - & - & - \\
\hline 6.53 & - & 4.31 & - & - & 4.43 & - & 17.78 & 2.85 & - & - & - & - & - \\
\hline 13.24 & - & 2.82 & - & - & $\ldots$ & - & 6.00 & 2.73 & - & - & - & - & - \\
\hline 22.39 & - & 8.67 & - & - & - & - & 7.78 & 1.71 & - & - & - & - & - \\
\hline 19.69 & - & 7.86 & - & - & - & - & 6.62 & 2.16 & - & 1.01 & - & - & - \\
\hline 29.65 & - & 4.98 & - & - & - & - & 4.63 & - & - & - & 1.49 & - & - \\
\hline 24.39 & - & 9.23 & - & - & - & - & 2.73 & 10.40 & - & - & - & - & - \\
\hline 32.41 & - & 11.45 & - & - & - & - & 3.08 & 3.99 & 1.37 & - & - & - & - \\
\hline 30.89 & - & 9.42 & - & - & - & - & 3.61 & 4.50 & 1.19 & - & - & - & - \\
\hline 24.54 & - & 8.67 & - & - & - & - & 2.90 & 12.42 & - & - & 1.38 & - & - \\
\hline 24.58 & - & 7.77 & - & - & - & - & 2.23 & 1.05 & - & - & - & - & - \\
\hline 4.92 & 2.91 & 6.67 & - & - & 1.67 & 1.04 & 12.58 & 11.18 & 1.74 & - & - & 1.17 & - \\
\hline 11.00 & 1.75 & 8.22 & - & - & - & - & 12.41 & 6.56 & 1.80 & - & - & 1.22 & - \\
\hline 10.62 & 1.73 & 7.25 & - & - & 1.36 & 1.11 & 12.29 & 5.07 & 1.92 & - & - & 1.02 & - \\
\hline
\end{tabular}

and $L$. rubrilucens belong to two distinct genomic species, they are nevertheless closely related $(3,21)$. In fact, some strains assigned to L. erythra are serologically indistinguishable from L. rubrilucens strains (21), indicating that further moleculargenetic studies should be performed with these two species.

Cluster 5, which was defined at a similarity level of $78 \%$, included the type strain of Legionella sainthelensi, 29 unidentified isolates obtained from one hot spring in Portugal, 2 isolates identified by IFA as $L$. sainthelensi strains, and 2 isolates identified as Legionella santicrucis strains. The last four isolates produced strong cross-reactions in IFA tests with strains of either species, and their identities were considered tentative. These isolates have fatty acid compositions that are distinct from the fatty acid compositions of the type strains of $L$. sainthelensi and $L$. santicrucis (Table 3 ), but the SDS-PAGE results showed that these organisms, which originated from four different geothermal areas, have protein patterns that are indistinguishable from those of $L$. sainthelensi strains and probably are members of this species. Our results also showed that the type strain of $L$. santicrucis has a distinct SDS-PAGE protein profile.

Clusters $6,7,17,18$, and 19 included the type and reference strains of (and in most cases, isolates identified as) Legionella longbeachae, Legionella jordanis, Legionella hackeliae, Legio- nella brunensis, and Legionella moravica, respectively. These clusters formed at levels of similarity that varied between 83 and $88 \%$. L. micdadei ATCC 33218 ${ }^{\mathrm{T}}$ and ATCC 33204 and seven isolates obtained from thermal areas in the Azores and continental Portugal formed cluster 20 at a similarity level of $75 \%$.

Clusters 21 and 22 were composed of strains of Legionella nautarum and Legionella londiniensis, respectively. Our isolates were identified initially by IFA as $L$. londiniensis strains by using antisera obtained from the Centre National de Référence des Legioneloses, Lyon, France $(19,29)$, but $L$. nautarum NCTC $12375^{\mathrm{T}}$, which was obtained on two separate occasions, belonged to an SDS-PAGE cluster that exhibited a high level of similarity with our isolates. Antisera to $L$. nautarum and $L$. londiniensis were also obtained from the National Collection of Type Cultures, and these antisera produced contradictory results which led to the identification of our isolates as $L$. nautarum strains. When the type strains of these two species became available from the American Type Culture Collection, we verified that $L$. londiniensis ATCC $49505^{\mathrm{T}}$ and $L$. nautarum NCTC $12375^{\mathrm{T}}$ produced identical whole-protein SDS-PAGE profiles (level of similarity, 98\%), while $L$. nautarum ATCC $49506^{\mathrm{T}}$ produced an SDS-PAGE profile similar to that of $L$. londiniensis NCTC $12374^{\mathrm{T}}$ and may represent a different 


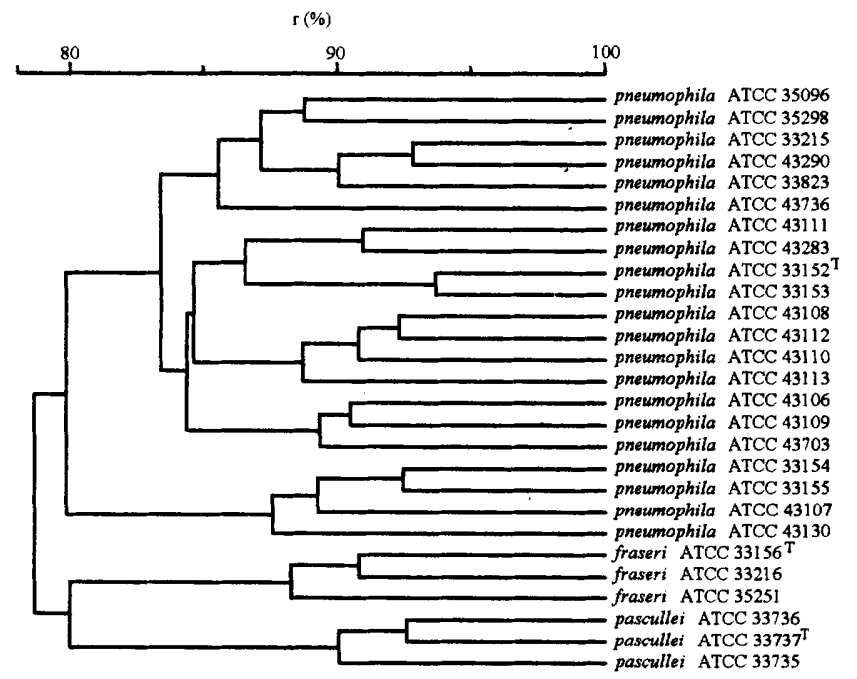

FIG. 3. Dendrogram based on unweighted pair group average linkage of correlation coefficients ( $\mathrm{r}$ ) of the protein patterns of $L$. pneumophila reference strains. The dendrogram was produced by using points 10 to 226 and 259 to 330 on the electrophoretic traces. The names of the three $L$. pneumophila subspecies are indicated by their subspecific epithets.

strain (level of similarity, $82 \%$ ). Moreover, the results of our analyses of the respiratory quinones and fatty acids clearly confirmed that the strains obtained from the National Collection of Type Cultures do not correspond to L. londiniensis and L. nautarum, as described by Dennis et al. (5), or to the type strains deposited in the American Type Culture Collection (Tables 2 and 3). It should be noted, however, that the chemotaxonomic parameters of the type strains deposited in the National Collection of Type Cultures correspond to those of the two species reported initially (33). Therefore, it will be necessary to obtain complete histories of these strains to clarify the origins of the strains deposited in the National Collection of Type Cultures which do not correspond to the strains deposited in the American Type Culture Collection.

For 18 species, only the type strains were available, and none of these organisms except $L$. geestiana, belonged to a cluster that included other species. In a few cases, a species represented by only the type strain produced an SDS-PAGE profile that was similar to the profiles produced by members of a cluster formed by strains belonging to another species. For example, the level of similarity for Legionella quinlivanii ATCC $43830^{\mathrm{T}}$ and L. birminghamensis was $84 \%$. Other strains that are not available now will have to be examined to ascertain if this method can be used to identify these species.

With the exception of the strains of $L$. bozemanii, which had two electrophoretic types, and the type strain of $L$. geestiana, which clustered with $L$. feeleii as determined by the standard method of numerical analysis in which points 10 to 330 of the traces were used, all of the type strains could be distinguished from one another by the method which we used. Some of the isolates could not be identified by IFA, but the vast majority of the isolates and reference strains were included in a cluster that contained the type strain of a species. The assignments of the isolates to species were generally supported by the results of the fatty acid and ubiquinone composition analyses, indicating that computer-assisted SDS-PAGE is a useful method for identifying isolates. Our data also show that deletion of small zones from electrophoretic traces can greatly improve species discrimination and result in identification of all of the type strains of the species of the genus Legionella. The large number of reference strains and isolates of $L$. pneumophila that belong to one cluster provides a suitable example of the resolution of the method.

On the basis of our results, we concluded that computerassisted whole-protein SDS-PAGE can be used in taxonomic studies of Legionella species, particularly because phenotypic characteristics and fatty acid and respiratory quinone analysis data cannot be used to distinguish most Legionella species.

\section{ACKNOWLEDGMENTS}

This study was supported in part by grant JNICT 43/INF/87 from the Junta Nacional de Investigação Científica e Tecnológica and by the Sociedade das Águas de Luso, S. A.

We thank K. Kersters and B. Pot (Laboratorium voor Microbiologie, Universiteif Gent, Ghent, Belgium) for helpful discussions and advice.

\section{REFERENCES}

1. Bangsborg, J. M., P. Gerner-Smidt, H. Colding, N.-E. Fiehn, B. Bruun, and N. Hoiby. 1995. Restriction fragment length polymorphism of rRNA genes for molecular typing of members of the family Legionellaceae. J. Clin. Microbiol. 33:402-406,

2. Brenner, D. J., A. G. Steigerwalt, P. Epple, W. F. Bibb, R. M. McKinney, R. W. Starnes, J. M. Colville, R. K. Selander, P. H. Edelstein, and C. W. Moss. 1988. Legionella pneumophila serogroup Lansing 3 isolated from a patient with fatal pneumonia, and descriptions of $L$. pneumophila subsp. pneumophila subsp. nov., $L$. pneumophila subsp. fraseri subsp. nov., and $L$. pneumophila subsp pascullei subsp, nov. J. Clin. Microbiol. 26:1695-1703.

3. Brenner, D. J., A. G. Steigerwalt, G. W. Gorman, H. W. Wilkinson, W. F. Bibb, M. Hackel, R. L. Tyndall, J. Campbell, J. C. Feeley, W. L. Thacker, P. Skaliy, W. T. Martin, B. J. Brake, B. S. Fields, H. V. McEachern, and L. K. Corcoran, 1985. Ten new species of Legionella. Int. J. Syst. Bacteriol. 35:5059.

4. Brown, A., G. M. Garrity, and R. M. Vickers. 1981. Fluoribacter dumoffii (Brenner et al.) comb. nov. and Fluoribacter gormanii (Morris et al.) comb. nov. Int. J. Syst. Bacteriol. 31:111-115.

5. Dennis, P. J., D. J. Brenner, W. L. Thacker, R. Wait, G. Vesey, A. G. Steigerwalt, and R. F. Benson. 1993. Five new Legionella species isolated from water. Int. J. Syst. Bacteriol. 43:329-337.

6. Edelstein, P. H. 1987. Laboratory diagnosis of infections caused by Legionellae. Eur. J. Clin. Microbiol. 6:4-10.

7. Fox, K. F., A. Brown, A. Fox, and G. Schnitzer. 1991. Tatlokia, a genetically and chemically distinct group of bacteria. Proposal to transfer Legionella maceachernii (Brenner et al.) to the genus Tatlockia, as Tatlockia maceachernii comb. nov. Syst. Appl. Microbiol. 14:52-56.

8. Fraser, D. W., T. R. Tsai, W. Orenstein, W. E. Parkin, H. J. Beecham, R. G. Sharrer, J. Harris, G. F. Mallison, S. M. Martin, J. E. McDade, C. C. Shepard, P. S. Bracham, and the Field Investigation Team. 1977. Legionnaires' disease: description of an epidemic of pneumonia. N. Engl. J. Med. 297:1189-1197.

9. Garrity, G. M., A. Brown, and R. M. Vickers. 1980. Tatlockia and Fluoribacter: two new genera of organisms resembling Legionella pneumophila. Int. J. Syst. Bacteriol. 30:609-614.

10. Glick, T. H., M. B. Gregg, B. Berman, G. Mallison, W. W. Rhodes, and I. Kassanoff. 1978. Pontiac fever: an epidemic of unknown etiology in a health department. I. Clinical and epidemiological aspects. Am. J. Epidemiol. 107: 149-160.

11. Grimont, F., M. Lefêvre, E. Ageron, and P. A. D. Grimont. 1989. rRNA gene restriction patterns of Legionella species: a molecular identification system. Res. Microbiol. 140:615-626.

12. Joly, J. R., R. M. McKinney, J. O. Tobin, W. F. Bibb, I. D. Watkins, and D. Ramsay. 1986. Development of a standardized subgrouping scheme for Legionella pneumophila serogroup 1 using monoclonal antibodies. J. Clin. Microbiol. 23:768-771.

13. Kersters, K., and J. De Ley. 1975. Identification and grouping of bacteria by numerical analysis of their protein patterns. J. Gen. Microbiol. 87:333-342.

14. Kiredjian, M., B. Holmes, K. Kersters, I. Guilvout, and J. De Ley. 1986. Alcaligenes piechaudii, a new species from human clinical specimens and the environment. Int. J. Syst. Bacteriol. 36:282-287.

15. Kuykendall, L. D., M. A. Roy, J. J. O'Neill, and T. E. Devine. 1988. Fatty acids, antibiotic resistance, and deoxyribonucleic acid homology groups of Bradyrhizobium japonicum. Int. J. Syst. Bacteriol. 38:358-361.

16. Laemmli, U. K. 1970 . Cleavage of structural proteins during the assembly of the head of bacteriophage T4. Nature (London) 227:680-685.

17. Lambert, M. A., and C. W. Moss. 1989. Cellular fatty acid compositions and isoprenoid quinone contents of 23 Legionella species. J. Clin. Microbiol. 27:465-473.

18. Lema, M., and A. Brown. 1983. Electrophoretic characterization of soluble 
protein extracts of Legionella pneumophila and other members of the family Legionellaceae. Appl. Environ. Microbiol 17:1132-1140.

19. Marrão, G., A. Veríssimo, R. G. Bowker, and M. S. da Costa. 1993. Biofilms as major sources of Legionella spp. in hydrothermal areas and their dispersion into stream water. FEMS Microbiol. Ecol. 12:25-33.

20. McDade, J. E., C. C. Shepard, D. W. Fraser, T. R. Tsai, M. A. Redus, W. R. Dowdle, and the Laboratory Investigation Team. 1977. Legionnaires' disease: isolation of a bacterium and demonstration of its role in respiratory disease. N. Engl. J. Med. 297:1197-1203.

21. Saunders, N. A., N. Doshi, and T. G. Harrison. 1992. A second serogroup of Legionella enthra serologically indistinguishable from Legionella rubrilucens. J. Appl. Bacteriol. 72:262-265.

22. Saunders, N. A., T. G. Harrison, N. Kachwalla, and A. G. Taylor. 1988 Identification of species of the genus Legionella using a cloned rRNA gene from Legionella pneumophila. J. Gen. Microbiol. 134:2363-2374.

23. Selander, R. K., R. M. McKinney, T. S. Whittam, W. F. Bibb, D. J. Brenner F. S. Nolte, and P. E. Pattison. 1985. Genetic structure of populations of Legionella pneumophila. J. Bacteriol. 163:1021-1037.

24. Sokal, R. R., and P. H. A. Sneath. 1963. Principles of numerical taxonomy. W. H. Freeman and Co., San Francisco.

25. Stout, J. E., J. Joly, M. Para, J. Plouffe, C. Ciesielki, M. J. Blaser, and V. L. Yu. 1988. Comparison of molecular methods for subtyping patients and epidemiologically linked environmental isolates of Legionella pneumophila. J. Infect. Dis. 157:486-495.

26. Tindall, B. J. 1989. Fully saturated menaquinones in the archaebacterium Pyrobaculum islandicum. FEMS Microbiol. Lett. 60:251-254.

27. Vauterin, L., R. Vantomme, B. Pot, B. Hoste, J. Swings, and K. Kersters 1990. Taxonomic analysis of Xanthomonas campestris pv. begoniae and $X$ campestris pv. pelargonii by means of phytopathological, phenotypic, protein electrophoretic and DNA hybridization methods. Syst. Appl. Microbiol. 13: $166-176$.
28. Vauterin, L., and P. Vauterin. 1992. Computer-aided objective comparison of electrophoresis patterns for grouping and identification of microorganisms. Eur. Microbiol. 1:37-41.

29. Veríssimo, A., G. Marrão, F. G. da Silva, and M. S. da Costa. 1991. Distribution of Legionella spp. in hydrothermal areas in continental Portugal and the island of São Miguel, Azores. Appl. Environ. Microbiol. 57:29212927.

30. Veríssimo, A., G. Vesey, G. M. Rocha, G. Marrão, J. Colbourne, P. J. Dennis, and M. S. Costa. 1990. A hot water supply as the source of Legionella pneumophila in incubators of a neonatology unit. J. Hosp. Infect. 15:255-263.

31. Vesey, G., P. J. Dennis, J. V. Lee, and A. A. West. 1988. Further development of simple tests to differentiate the legionellas. J. Appl. Bacteriol. 65:339-345.

32. Vickers, R. M., and V. L. Yu. 1984. Clinical laboratory differentiation of Legionellaceae family members with pigment production and fluorescence on media supplemented with aromatic substrates. J. Clin. Microbiol. 19:583587.

33. Wait, R. 1988. Confirmation of the identity of Legionellae by whole cell fatty-acid and isoprenoid quinone profiles, p. 69-101. In T. G. Harrison and A. G. Taylor (ed.), A laboratory manual for Legionella. John Wiley \& Sons, Ltd., London.

34. Watkins, I. D., J. O. Tobin, P. J. Dennis, W. Brown, R. S. Newnham, and J. B. Kurtz. 1985. Legionella pneumophila serogroup 1 subgrouping by monoclonal antibodies-an epidemiological tool. J. Hyg. 95:211-216.

35. Wilkinson, I. J., N. Sangster, R. M. Ratcliff, P. A. Mugg, D. E. Davos, and J. A. Lanser. 1990. Problems associated with identification of Legionella species from the environment and isolation of six possible new species. Appl. Environ. Microbiol. 56:796-802.

36. Woods, T. C., R. M. McKinney, B. D. Plikaytis, A. G. Steigerwalt, W. F. Bibb, and D. J. Brenner. 1988. Multilocus enzyme analysis of Legionella dumoffii. J. Clin. Microbiol. 26:799-803. 